\title{
New and known type 2 diabetes as coronary heart disease equivalent: results from 7.6 year follow up in a middle east population
}

\author{
Farzad Hadaegh ${ }^{1 *}$, Nooshin Fahimfar ${ }^{1}$, Davood Khalili, ${ }^{1,2}$, Farhad Sheikholeslami', Fereidoun Azizi ${ }^{3}$
}

\begin{abstract}
Background: To investigate whether the known diabetes mellitus (KDM) or newly diagnosed diabetes mellitus (NDM) could be regarded as a coronary heart disease (CHD) risk equivalent among a relatively young Middle East population with high prevalence of diabetes mellitus (DM).

Methods: A population based cohort study of 2267 men and 2931 women, aged $\geq 30$ years. Prior CHD was defined as self-reported or ECG positive CHD at baseline, KDM as subjects using any kind of glucose-lowering medications and NDM according to fasting plasma glucose and 2-h postchallenge glycemia.

Participants were categorized to six groups according to the presence of known or newly diagnosed DM and CHD at baseline (DM-/CHD-, DM-/CHD+, NDM+/CHD-, NDM+/CHD+, KDM+/CHD-, KDM+/CHD+) and Cox regression analysis were used to estimate the hazard ratio (HR) of CHD events for these DM/CHD groups, given DM-/CHD-as the reference.

Results: During 7.6-year follow up, $358 \mathrm{CHD}$ events occurred. After controlling traditional risk factors, HRs of CHD events for DM-/CHD+ group were 2.1 (95\% Cl: 1.4-3.1) and 5.2 (3.2-8.3) in men and women respectively.

Corresponding HRs for NDM+/CHD-were 1.7 (1.1-2.7) and 3.1 (1.8-5.6) and for KDM+/CHD-were 1.7 (0.9-3.3) and 6.2 (3.6-10.6) in men and women respectively. The HRs for NDM+/CHD+ and KDM+/CHD+ groups (i.e. participants with history of both diabetes and CHD) were 6.4 (3.2-12.9) and 8.0 (4.3-14.8) in women and 3.2 (1.9-5.6) and 4.2 (2.2-7.8) in men, respectively.

The hazard of $\mathrm{CHD}$ events did not differ between KDM+/CHD-and DM-/CHD+ in both genders using paired homogeneity test, however the HR for NDM+/CHD-was marginally lower than the HR for DM-/CHD+ in women $(p=0.085)$.

Conclusions: KDM patients in both genders and NDM especially in men exhibited a CHD risk comparable to nondiabetics with a prior $\mathrm{CHD}$, furthermore diabetic subjects with prior $\mathrm{CHD}$ had the worst prognosis, by far more harmful in women than men; reinforcing the urgent need for intensive care and prophylactic treatment for cardiovascular diseases.
\end{abstract}

\section{Background}

The most important cause of mortality in diabetic patients is cardiovascular disease (CVD) [1] and observational studies have shown that diabetes mellitus (DM) increases risk of CVD nearly two to three folds [1,2]. In addition, some cohort studies conducted in American

\footnotetext{
* Correspondence: fzhadaegh@endocrine.ac.ir

'Prevention of Metabolic Disorders Research Center, Research Institute for Endocrine Sciences, Shahid Beheshti University of Medical Sciences,

Parvaneh St., Yaman St., Velenjak, Tehran, Iran

Full list of author information is available at the end of the article
}

and European populations have suggested that rates for coronary heart disease (CHD) events are equivalent to both individuals with prior CHD and diabetic subjects without prior CHD [1-4]. Therefore, the American Diabetes Association recommended that, in secondary prevention, the diabetic patients should be treated for the same lipid and blood pressure targets as subjects with previous myocardial infarction [5]. Some other studies have found that cardiovascular risk are lower in subjects with diabetes but without CHD, than in persons with CHD and without diabetes [6-8]; however a few studies 
have also shown contradictory results [2,3]. Importantly, it is not clear whether these findings can be generalized to other populations because relative mortality risks may differ with ethnicity [9-11].

It is estimated that developing countries in Asia and in the Middle East, particularly in Persian Gulf states, will have the largest increases in the prevalence of diabetes by 2030, which is related to major shift in life style and nutrition transition in these countries [12-17]. Nevertheless, to our best knowledge, there is no study to show the equivalency of diabetes and prior CHD for risk of $\mathrm{CHD}$ in this region.

The prevalence of Type 2 diabetes is reported to be more than $14 \%$ in Tehran, Iran, with an estimated incidence of new cases in about $1 \%$ of the population per year $[14,15]$. There is a high prevalence of CHD in this area too [18] and it has been shown that the Iranian population with diabetes has a high risk for CVD, independent of traditional risk factors [19]. Hence, we compared the risk of CHD events among diabetic participants without prior CHD to that of participants diagnosed as having CHD but not diabetes in the framework of the Tehran Lipid and Glucose Study (TLGS) which is a population based study conducted on a representative population of the capital city, Tehran [20]. Furthermore, we analyzed the results separately for newly diagnosed DM and known DM, and in addition to a prior history of CHD, we applied electrocardiographic criteria for the presence of CHD at baseline.

\section{Methods}

\section{Study population}

The TLGS is a prospective population-based study to determine the risk factors for non-communicable diseases among a representative urban population of Tehran [20]. The sampling method has been described elsewhere [20]. Briefly, a total of 15005 individuals aged 3 years and over who were residences of district No.13 of Tehran were selected using multistage cluster random sampling method. Subjects were categorized into the cohort and intervention groups, the latter to be educated for implementation of life style changes [20]. From among 8071 individuals, aged $\geq 30$ years, who participated in the first phase of TLGS (February 1999 to August 2001), 5981 subjects had complete data of electrocardiogram (ECG) and history of CHD. Excluding participants with other missing data $(\mathrm{n}=$ 155) resulted in 5826 subjects at baseline; of those we followed 5198 (64.4\% of total) until 20 March 2008 with a median follow up of 7.6 years (Figure 1). Written informed consent was obtained from all subjects and the ethical committee of Research Institute for Endocrine Sciences approved this study.

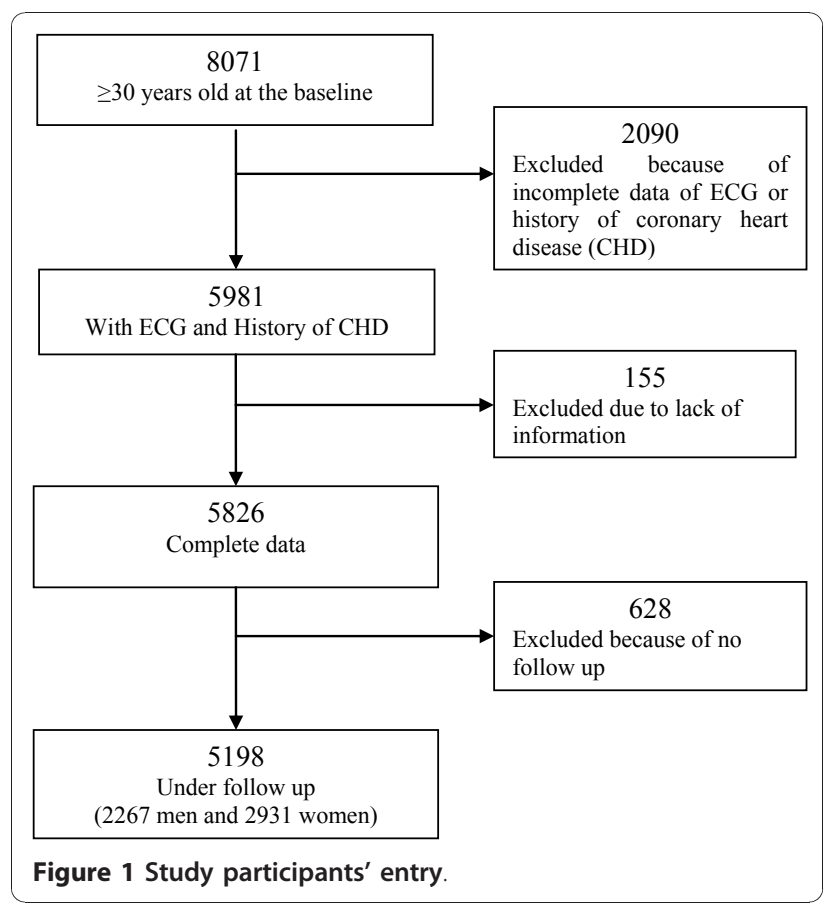

Clinical and laboratory measurements at enrolment

The information was collected during a personal interview, and completion of a questionnaire for demographic factors, medical history, medication use and smoking. Physical examination for blood pressure and anthropometrical measurements was performed. Blood pressure was measured twice in a seated position after 15 min resting using a standard mercury sphygmomanometer and the mean of the two measurements was considered as the subject's blood pressure. Body mass index (BMI) was calculated as weight $(\mathrm{kg})$ divided by the square of height $\left(\mathrm{m}^{2}\right)$.

Two trained technicians recorded a 12-lead ECG according to the standard recording protocol developed by the School of Public Health, the University of Minnesota using a PC-ECG 1200 machine [21]. Two qualified physicians coded the ECGs in parallel according to the Minnesota codes using a measuring loupe specially manufactured by University of Minnesota [21]. Then, for assurance of quality a third qualified physician recoded $10 \%$ of ECGs. All the data were double-checked.

Fasting plasma glucose (FPG) and lipid profiles were tested after 12-14 hours overnight fasting. Standard oral glucose tolerance test (OGTT) was performed in participants without treated diabetes. All analyses were done at the TLGS research laboratory on the day of collection. Plasma glucose, serum total cholesterol, highdensity lipoprotein cholesterol (HDL-C) and triglyceride (TG) levels were measured by using previously reported methods [20]. 


\section{Definition of terms}

Family history of premature CVD reflected prior diagnosis of CVD in female first-degree relatives, aged less than 65 years or male first-degree relatives under the age of 55 years old.

Smoking was defined as history of current smoking (including daily or occasional). Newly diagnosed DM (NDM) was defined as individuals with FPG $\geq 7.0$ $\mathrm{mmol} / \mathrm{L}(126 \mathrm{mg} / \mathrm{dl})$ or 2 -h postchallenge glycemia $(2 \mathrm{hPG}) \geq 11.1 \mathrm{mmol} / \mathrm{L}(200 \mathrm{mg} / \mathrm{dl})$ without any history of glucose-lowering medications and Known DM (KDM) was defined as subjects who have been treated with any kind of glucose-lowering medications.

\section{Prevalent CHD at enrolment}

Prevalent (or prior) CHD was defined as self-reported CHD or ECG positive CHD. Self-reported CHD was defined as a positive answer to the question as to "whether the subject has ever had a prior diagnosis of CHD by a physician". Electrocardiogram positive CHD was defined according to the Whitehall criteria [22] which categorize subjects into three groups, non CHD, probable CHD (any Minnesota codes of 1.1.1 through 1.1.7and 1.2.1 through 1.2.8) and possible CHD (codes of 1.3.1 through 1.3.6, 4.1.1 through 4.4, 5.1 through 5.3 or 7.1.1 through 7.1.2). In our analysis, we considered both probable and possible CHD as a single definition of ECG-positive CHD.

We divided our cohort into six groups based on their clinical status at the baseline examination:

- Subjects without newly diagnosed or known DM and without prior CHD (DM-/CHD-)

- Subjects without newly diagnosed or known DM but with prior CHD (DM-/CHD+)

- Subjects with NDM but without prior CHD (NDM + (CHD-)

- Subjects with NDM and with prior CHD (NDM $+/ \mathrm{CHD}+$ )

- Subjects with KDM but without prior CHD (KDM + (CHD-)

- Subjects with KDM and with prior CHD (KDM $+/ \mathrm{CHD}+)$

\section{Definition of CHD outcome}

Each TLGS participant is under continuous surveillance for any medical event leading to hospitalization during the previous year by telephone call and he/she is questioned by a trained nurse regarding any medical conditions. If a related event has occurred, a trained physician collects complementary data during a home visit, and when deemed necessary, a visit to the respective hospital for collecting data from the participant's medical files was done. In the case of mortality, data are collected from the hospital or death certificate by an authenticated local physician. Collected data are evaluated by an outcome committee consisting of a principal investigator, an internist, an endocrinologist, a cardiologist, an epidemiologist and the physician who collected the outcome data; other experts are invited for evaluation of non-communicable disorders as needed. Specific outcome for every event is assigned according to ICD-10 criteria and American Heart Association classification for cardiovascular events [20].

In the current study, CHD events as outcomes included cases of definite myocardial infarction (MI) diagnosed by electrocardiogram (ECG) and biomarkers, probable MI (positive ECG findings plus cardiac symptoms or signs but biomarkers showing negative or equivocal results), unstable angina pectoris (new cardiac symptoms or changing symptom patterns and positive ECG findings with normal biomarkers), angiographic proven $\mathrm{CHD}$ and $\mathrm{CHD}$ death.

\section{Statistics}

The results for continues variables are given as mean $( \pm \mathrm{SD})$ and for categorical variables as percentages. Comparisons of the baseline characteristics among DM/ CHD groups were done using ANOVA or $\chi 2$ test and we used t-test or $\chi 2$ test to compare any group with the $\mathrm{DM}-/ \mathrm{CHD}+$ group considering Bonferroni correction for multiple comparisons.

Cox proportional hazard regression models were used to estimate the hazard ratio (HR) of CHD events for $\mathrm{DM} / \mathrm{CHD}$ groups (DM-/CHD+, NDM+/CHD-, NDM $+/ \mathrm{CHD}+, \mathrm{KDM}+/ \mathrm{CHD}-, \mathrm{KDM}+/ \mathrm{CHD}+)$ in both genders, given DM-/CHD-as the reference group. Follow up duration was defined as the period between the entrance to study and the end point; end point was considered as the first CHD event and participants were censored at non-CHD death or end of follow-up. Analyses were done with adjustment for age alone and for age with other possible risk factors including systolic blood pressure, body mass index (BMI), total cholesterol, TG/ HDL-C [23], family history of premature CVD, smoking and being in the intervention group. The proportional hazards assumption in the Cox model was assessed using $\log$ minus log plot of survival and Schoenfeld residual test. All proportional hazards assumptions were generally appropriate ( $\mathrm{p}$-value for global test of proportional hazards assumption was $>0.1$ in men and women).

A paired homogeneity test, which is a Wald test of the linear hypothesis of the Cox model regression coefficients, was performed to test the null hypothesis that the hazard ratio for NDM+/CHD-and KDM+/CHD-was equal to that for DM-/CHD+.

Statistical analyses were performed using SPSS for windows version 15 and STATA version 10, and 
p-values less than 0.05 were considered statistically significant. All analyses were separated by gender regarding significant interaction between gender and some of the DM/CHD categories to predict CVD events.

\section{Results}

In comparison to men who were not included in the study, those who were had less history of smoking (27\% vs. $31.5 \%$ ). Women included were younger (46.9 vs. 47.8 years), had lower systolic blood pressure (122 vs. 124 $\mathrm{mmHg})$ and higher BMI (28.6 vs. $28.1 \mathrm{~kg} / \mathrm{m} 2)$ than those not included (all $\mathrm{p}<0.05$ ).

Baseline characteristics for all groups are shown in Table 1 and 2. Compared to the DM-/CHD+ group, $\mathrm{NDM}+/ \mathrm{CHD}$-had higher TG/HDL-C and BMI values in men and higher TG/HDL-C, BMI and systolic blood pressure values in women; also KDM+/CHD-had higher systolic blood pressure and TG/HDL-C in women.

Overall, 212 (9.4\%) men and 146 (5\%) women had CHD events during 16033 and 21433 person-years of follow up; the corresponding incidence density of CHD event were 13.2 and 6.8 per 1000 person-years in men and women respectively. In men, 46 (20.2\%) of DM-/ $\mathrm{CHD}+, 26(17.1 \%)$ of $\mathrm{NDM}+/ \mathrm{CHD}$-and $11(15.9 \%)$ of $\mathrm{KDM}+/ \mathrm{CHD}$-individuals experienced CHD events; these values in women were 39 (13.7\%), 19 (9.0\%) and 25 (18.1\%) respectively.

Table 3 and 4 and Figure 2 highlight the HR of coronary heart disease in relation with DM and prior CHD in men and women. Age adjusted analysis revealed notably higher risks in DM-/CHD+, NDM+/CHD-and KDM +/CHD-groups compared with DM-/CHD-in both genders. However, in multivariate analysis, $\mathrm{DM}-/ \mathrm{CHD}+$ and
$\mathrm{NDM}+/ \mathrm{CHD}$-in both genders and $\mathrm{KDM}+/ \mathrm{CHD}$-only in women remained as significant predictors of CHD events. The risks of patients with DM or CHD were higher in women than men (in all of the DM/CHD categories) and $p$-value for the effect modification by gender reached the significant level of 0.05 in DM-/CHD+ and $\mathrm{KDM}+/ \mathrm{CHD}$-groups ( $p=0.002$ for both). Hazard ratios of CHD events were 2.1 (95\%CI: 1.4-3.1), 1.7 (1.1-2.7) and 1.7 (0.9-3.3) for $\mathrm{DM}-/ \mathrm{CHD}+, \mathrm{NDM}+/ \mathrm{CHD}$-and $\mathrm{KDM}+$ /CHD-respectively in men, values which were 5.2 (3.2-8.3), 3.1 (1.8-5.6) and 6.2 (3.6-10.6) in women.

Considering both NDM and KDM in a DM+/CHDgroup, the HR of this group was 1.73 (95\%CI: 1.15-2.60) and 4.37 (2.74-6.97) compared to DM-/CHD-group in men and women, respectively.

Individuals with known or newly diagnosed DM and prior CHD demonstrated additive risks, i.e. HRs of 3.2 (95\% CI: 1.9-5.6) and 4.2 (2.2-7.8) in men and 6.4 (3.2$12.9)$ and $8.0(4.3-14.8)$ in women for $\mathrm{NDM}+/ \mathrm{CHD}+$ and $\mathrm{KDM}+/ \mathrm{CHD}+$ respectively.

Finally, as shown in Table 3 and 4, the results of the Wald test, used to compare the hazard ratios, highlighted that the risk of CHD events did not differ between $\mathrm{KDM}+/ \mathrm{CHD}$-and $\mathrm{DM}-/ \mathrm{CHD}+$ in both genders, however the risk of $\mathrm{NDM}+/ \mathrm{CHD}$-was marginally lower than the HR of DM-/CHD+ in women $(p=0.085)$.

\section{Discussion}

When history of CHD or ischemic ECG changes was used to define prior CHD, this study showed that Type 2 diabetes is a "CHD equivalent" in a 7.6-year follow-up of Iranian subjects. The risk of CHD associated with diabetes was relatively equal to that associated with

Table 1 General characteristics of men according to DM and prior CHD status at baseline ${ }^{\text {a }}$

\begin{tabular}{|c|c|c|c|c|c|c|}
\hline \multirow[b]{2}{*}{ Variable $^{b}$} & \multicolumn{5}{|c|}{ DM/CHD group } & \multirow[b]{2}{*}{$\mathrm{KDM}+/ \mathrm{CHD}+$} \\
\hline & DM-/CHD- & DM-/CHD+ & NDM+/CHD- & NDM+/CHD+ & KDM+/CHD- & \\
\hline number & 1726 & 228 & 152 & 52 & 69 & 40 \\
\hline Age (years) & $46.1(12.1)^{*}$ & $56.9(12.2)$ & $55.7(11.6)$ & $60.8(11.6)$ & $59.5(9.2)$ & $63.3(8.1)^{*}$ \\
\hline $\mathrm{SBP}(\mathrm{mm} \mathrm{Hg})$ & $119.3(17.0)^{*}$ & $131.8(23.0)$ & $132.1(20.5)$ & $144.1(32.0)^{*}$ & $132.4(20.4)$ & $139.9(27.6)$ \\
\hline DBP (mm Hg) & $78.0(10.7)^{*}$ & $80.8(12.8)$ & $82.0(12.5)$ & $84.3(15.7)$ & $80.5(10.3)$ & $81.65(13.3)$ \\
\hline $\mathrm{TC}(\mathrm{mmol} / \mathrm{L})$ & $5.39(1.07)^{*}$ & $5.78(1.16)$ & $5.86(1.21)$ & $5.83(1.08)$ & $5.60(1.26)$ & $5.61(1.07)$ \\
\hline TG/HDL-C & $5.3(4.5)^{*}$ & $6.1(4.6)$ & $7.2(4.6)^{*}$ & $7.5(7.0)$ & $7.5(6.9)$ & $4.8(3.2)$ \\
\hline BMI $\left(k g / m^{2}\right)$ & $25.9(3.8)^{*}$ & $27.0(3.7)$ & $28.0(3.9)^{*}$ & $27.6(3.7)$ & $27.6(4.0)$ & $26.1(3.4)$ \\
\hline Smoking (\%) & 29.0 & 21.1 & 20.4 & 32.7 & 20.3 & 17.5 \\
\hline FH of CVD (\%) & 14.8 & 18.4 & 13.2 & 13.5 & 11.6 & 12.5 \\
\hline Intervention (\%) & 38.0 & 36.8 & 38.2 & 40.4 & $58.0^{*}$ & 32.5 \\
\hline
\end{tabular}

${ }^{a}$ Data have been shown as mean $( \pm \mathrm{sd})$ or percent.

${ }^{b}$ In all variables except "FH of CVD" difference among categories is significant ( $\mathrm{P}<0.05$ according to ANOVA or $\chi 2$ test.)

*Difference with "Any DM-/CHD+" group is significant at the level of $\mathrm{P}<0.01$ (according to t-test or $\chi 2$ test and considering Bonferroni correction for multiple comparisons.).

DM: diabetes mellitus, CHD: coronary heart disease, NDM: newly diagnosed DM, KDM: known DM, SBP: systolic blood pressure, DBP: diastolic blood pressure, TC: total cholesterol, TG/HDL-C: triglyceride/HDL cholesterol, BMI: body mass index, FH of CVD: family history of premature cardiovascular disease, Intervention: being in intervention group. 
Table 2 General characteristics of women according to DM and prior CHD status at baseline ${ }^{\text {a }}$

\begin{tabular}{lllllll}
\hline & \multicolumn{7}{c}{ DM/CHD group } \\
\cline { 2 - 7 } Variable ${ }^{\mathbf{b}}$ & DM-/CHD- & DM-CHD+ & NDM+/CHD- & NDM+/CHD+ & KDM+/CHD- & KDM+/CHD+ \\
\hline number & 2184 & 285 & 210 & 56 & 138 & 58 \\
Age (years) & $44.6(10.7)^{*}$ & $53.0(11.7)$ & $51.2(10.0)$ & $57.2(8.3)^{*}$ & $55.4(9.6)$ & $60.6(7.8)^{*}$ \\
SBP (mm Hg) & $118.1(17.6)^{*}$ & $129.3(22.9)$ & $133.9(21.6)^{*}$ & $139.2(22.5)^{*}$ & $135.8(23.0)^{*}$ & $140.0(23.3)^{*}$ \\
DBP (mm Hg) & $78.1(10.0)^{*}$ & $82.4(12.5)$ & $84.5(11.8)$ & $85.6(9.7)$ & $82.6(10.5)$ & $81.5(12.2)$ \\
TC (mmol/L) & $5.61(1.15)^{*}$ & $6.14(1.26)$ & $6.24(1.25)$ & $6.53(1.57)$ & $6.34(1.32)$ & $6.87(1.33)^{*}$ \\
TG/HDL-C & $4.1(3.4)^{*}$ & $4.9(3.9)$ & $6.8(5.4)^{*}$ & $5.8(3.8)$ & $5.9(4.4)^{*}$ & $6.4(4.4)^{*}$ \\
BMI (kg/m $\left.{ }^{2}\right)$ & $28.2(4.6)^{*}$ & $29.3(4.8)$ & $30.6(4.9)^{*}$ & $30.1(5.0)$ & $29.2(4.8)$ & $29.4(5.2)$ \\
Smoking (\%) & 3.9 & 3.9 & 3.8 & 0.0 & 2.2 & 3.4 \\
FH of CVD (\%) & 17.5 & 22.1 & 26.2 & 16.1 & 23.2 & 25.9 \\
Intervention (\%) & 39.1 & 34.7 & 41.4 & 41.1 & 37.0 & 46.6
\end{tabular}

${ }^{a}$ Data have been shown as mean $( \pm \mathrm{sd})$ or percent.

${ }^{\mathrm{b}}$ In all variables except smoking and intervention difference among categories is significant $(\mathrm{P}<0.05$ according to ANOVA or $\chi 2$ test.)

*Difference with "Any DM-/CHD+" group is significant at the level of $\mathrm{P}<0.01$ (according to t-test or $\chi 2$ test and considering Bonferroni correction for multiple comparisons.).

DM: diabetes mellitus, CHD: coronary heart disease, NDM: newly diagnosed DM, KDM: known DM, SBP: systolic blood pressure, DBP: diastolic blood pressure, TC: total cholesterol, TG/HDL-C: triglyceride/HDL cholesterol, BMI: body mass index, FH of CVD: family history of premature cardiovascular disease, Intervention: being in intervention group.

prior CHD, each conferring a $\approx 2$ and $\approx 4$-fold increased risk of $\mathrm{CHD}$ in men and women, respectively. Our findings are consistent with the highly cited Haffner et al' paper, in which Finnish known Type 2 diabetic patients without prior myocardial infarction have as high a risk of myocardial infarction as nondiabetic patients with prior myocardial infarction [24]. Because the Haffner et al. study included only $69 \mathrm{DM}-/ \mathrm{CHD}+$ individuals, the power of the study to detect differences between the 2 groups was limited. Similarly, in a population based study in Denmark, diabetic patients requiring glucoselowering agents exhibited a cardiovascular risk comparable to nondiabetic with a prior myocardial infarction, regardless of sex and diabetes type [25]. However, Our findings are in contrast with those of Lee et al, in their Atherosclerosis Risk in Communities study (ARIC), in which after adjustment for multiple baseline risk factors, patients who had a history of myocardial infarction without diabetes at baseline had a 1.9 times the risk of fatal CHD or nonfatal myocardial infarction, compared with diabetic patients without a prior history of myocardial infarction [26]. Furthermore, in the Nurses' Health Study [27] and Health professional Follow-up study [8], Type 2 diabetic patients without myocardial infarction had a lower risk of CHD compared with myocardial infarction patients without diabetes. Recently, data from the REACH registry do not fully support the concept that diabetes is a cardiovascular risk equivalent, and the rate of pooled CVD mortality and nonfatal myocardial infarction in nondiabetic subjects with previous CAD was more than $50 \%$ higher than that seen in diabetic patients with risk factors only [28]. It is important to note that, the studies addressing these issues have great differences in age distribution, designs, and definitions of the study populations that could explain the discrepancies with our findings.

Recently we found that diabetes, in particular the known cases, had higher risk more so in women than in

Table 3 Hazard ratio of CHD event in men according to baseline DM and prior CHD status

\begin{tabular}{lccccc}
\hline & CHD event NO. (rate) & age adjusted HR & p-value & Multivariate $^{\mathbf{b}}$ adjusted HR & p-value \\
\hline DM-/CHD- & $98(7.8)$ & Ref & & Ref & \\
DM-/CHD+ & $46(30.5)$ & $2.8(1.9-4.0)$ & $<0.001$ & $2.1(1.4-3.1)$ & $<0.001$ \\
NDM+/CHD- & $26(25.5)$ & $2.4(1.5-3.7)$ & $<0.001$ & $1.7(1.1-2.7)^{*}$ & 0.020 \\
NDM+/CHD+ & $19(63.3)$ & $5.3(3.2-8.9)$ & $<0.001$ & $3.2(1.9-5.6)$ & $<0.001$ \\
KDM+/CHD- & $11(24.7)$ & $2.2(1.1-4.1)$ & 0.017 & $1.7(0.9-3.3) \dagger$ & 0.108 \\
KDM+/CHD+ & $12(55.5)$ & $4.7(2.5-8.7)$ & $<0.001$ & $4.2(2.2-7.8)$ & $<0.001$ \\
\hline
\end{tabular}

${ }^{a}$ Incidence rate: number of cases per 1000 person-year.

${ }^{\text {b }}$ Analyses were adjusted for age, systolic blood pressure, body mass index, cholesterol, triglyceride/HDL-cholesterol, family history of cardiovascular disease, smoking and intervention.

* The p-value to compare with the HR of DM-/CHD+ was 0.414 , applying Wald test.

† The p-value to compare with the HR of DM-/CHD+ was 0.527 , applying Wald test.

DM: diabetes mellitus, CHD: coronary heart disease, NDM: newly diagnosed DM, KDM: known DM, HR: hazard ratio. 
Table 4 Hazard ratio of CHD event in women according to baseline DM and prior CHD status

\begin{tabular}{lccccc}
\hline & CHD event NO. $(\text { rate })^{\mathbf{a}}$ & Age adjusted HR & p-value & Multivariate $^{\mathbf{b}}$ adjusted HR & p-value \\
\hline DM-/CHD- & $35(2.1)$ & Ref & & Ref & \\
DM-/CHD+ & $39(19.6)$ & $6.0(3.7-9.6)$ & $<0.001$ & $5.2(3.2-8.3)$ & $<0.001$ \\
NDM+/CHD- & $19(12.8)$ & $4.4(2.5-7.7)$ & $<0.001$ & $3.1(1.8-5.6)^{*}$ & $<0.001$ \\
NDM+/CHD+ & $11(30.4)$ & $8.2(4.1-16.4)$ & $<0.001$ & $6.4(3.2-12.9)$ & $<0.001$ \\
KDM+/CHD- & $25(26.5)$ & $7.4(4.4-12.6)$ & $<0.001$ & $6.2(3.6-10.6)+$ & $<0.001$ \\
KDM+/CHD+ & $17(48.2)$ & $11.3(6.1-20.8)$ & $<0.001$ & $8.0(4.3-14.8)$ & $<0.001$ \\
\hline
\end{tabular}

${ }^{a}$ Incidence rate: number of cases per 1000 person-year.

${ }^{b}$ Analyses were adjusted for age, systolic blood pressure, body mass index, cholesterol, triglyceride/HDL-cholesterol, family history of cardiovascular disease, smoking and intervention.

* The p-value to compare with the HR of DM-/CHD+ was 0.085 , applying Wald test.

† The $\mathrm{p}$-value to compare with the HR of DM-/CHD+ was 0.475 , applying Wald test.

DM: diabetes mellitus, CHD: coronary heart disease, NDM: newly diagnosed DM, KDM: known DM, HR: hazard ratio.

men for CVD events [19]. In the present study, according to the diabetes status i.e. new vs. known cases, in women both the $\mathrm{KDM}+/ \mathrm{CHD}$-and $\mathrm{NDM}+/ \mathrm{CHD}$-groups had significant risk for incident CHD in comparison with the DM-/CHD-group (Risk factor adjusted $\mathrm{HR} \approx 6$ and $\approx 3$ respectively, $\mathrm{p}<0.001$ ); however, in men only $\mathrm{NDM}+\mathrm{CHD}-$, resulted in a significant risk, in comparison with DM-/CHD-(HR: 1.7, 95\% CI: 1.07-2.69). The lack of association of $\mathrm{KDM}+/ \mathrm{CHD}$-with incident $\mathrm{CHD}$ in men might be attributed to the limited statistical power.

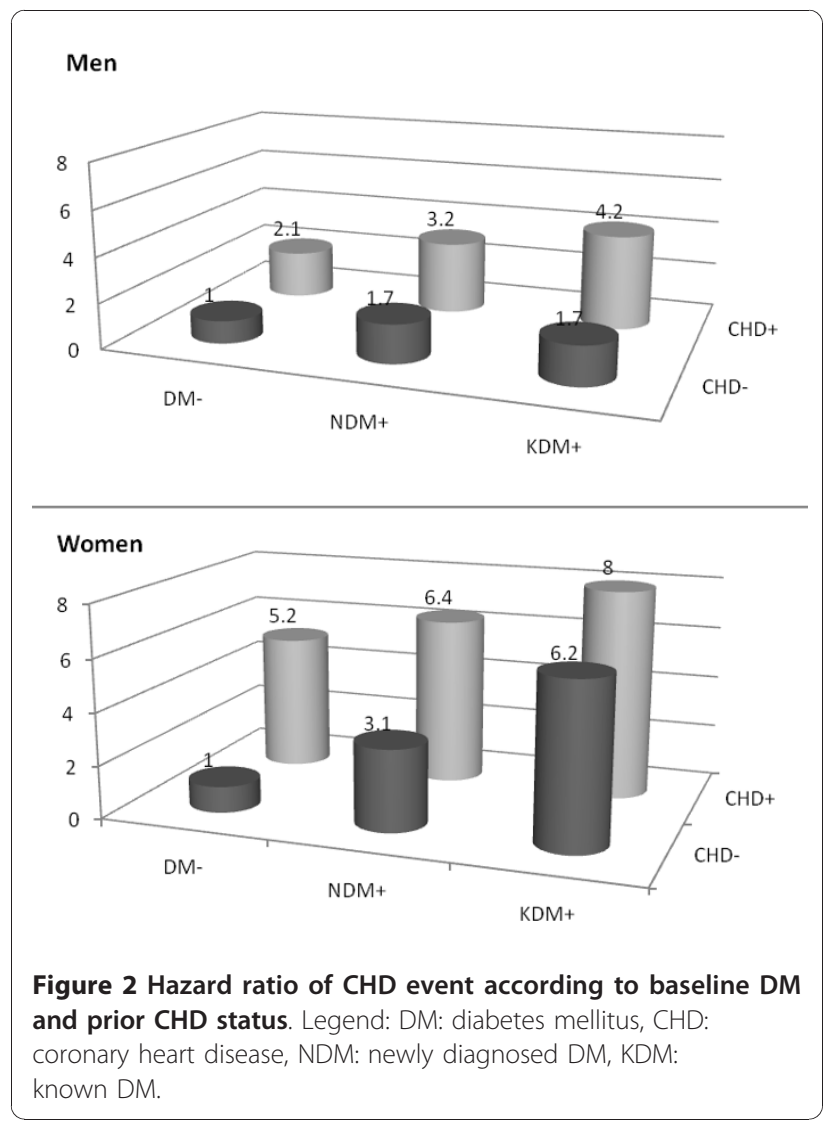

As acknowledged by Gonzalez-Clemente et al, it would probably have been better to directly compare persons who were $\mathrm{DM}+/ \mathrm{CHD}$-with those who were $\mathrm{DM}-/ \mathrm{CHD}+[29]$, hence comparing directly the hazard ratios of the these groups using the paired homogeneity test highlighted no difference between the KDM $+/ \mathrm{CHD}$-and $\mathrm{DM}-/ \mathrm{CHD}+$ groups in risk factor adjusted analysis in prediction of incident CHD. However, an important finding of the current study was that regarding NDM in women, the risk of incident CHD in multivariate analysis for participants with $\mathrm{DM}-/ \mathrm{CHD}+$ was marginally higher than those with NDM+/CHD-, although this did not reach a significant level. Consistent with our findings, a similar impact of diabetes in those receiving glucose-lowering agents (i.e. KDM) vs. those with prior CHD in prediction of incident CHD was demonstrated in the Multiple Risk Factor Intervention Trial (MRFIT) of men, 35 to 57 years old [30]. Similarly, Carnethon et al in a longitudinal study of men and women aged $\geq 65$ years highlighted that, CHD mortality risk was similar between participants with CHD alone vs. diabetes alone [31]. Recently Andrersson $\mathrm{el}$, in a multivariate regression analyses showed that patients with diabetes and absence of significant coronary artery disease at angiography have impaired systolic longitudinal left ventricular function and a global diastolic dysfunction, which is likely to be associated with adverse prognosis [32].

In the present study, diabetic subjects with prior $\mathrm{CHD}$ had the worst prognosis, by far more harmful in women than men (multivariate adjusted HR 7.19 vs. 3.58, respectively) similar to the reports of other studies $[2,27,29]$ highlighting the importance of secondary prevention in patients with both coexisting disorders, especially in women. Our data concerning higher risk of CVD in women than men with DM +/CHD+ is comparable with female sex predominance in acute coronary syndrome patients with diabetes from a hospital based study from Iran [33]. 
Our study has several strengths. This is the first population-based study in Caucasians of Middle East region, conducted to determine the equivalency of diabetes and prior CHD for risk of CHD event. We included newly diagnosed DM in our study based on the OGTT result; furthermore, the ischemic change of ECG was added for defining prevalent $\mathrm{CHD}$. However, most of the studies on this issue, included diagnosis of CHD and diabetes based on data provided by the patients themselves, which may have led to misclassification of subjects in the various groups. Finally, our study also adjusted for major CVD risk factors in the statistical model.

\section{Limitations of the study}

This study has important limitations that should be considered. First, we used positive history of CHD and the ECG-defined CHD as criteria to define prevalent CHD at baseline. The principal difference between these criteria might be caused by over reporting, non-Q-wave myocardial infarctions, or the interventions implemented to alleviate blockage of the coronary arteries [22]; unfortunately, at baseline the questionnaire of TLGS did not include questions about use of thrombolytic therapy, coronary artery bypass surgery, or percutaneous transluminal coronary angioplasty. Furthermore, populationbased studies have found self-reported MI, CHD and stroke to be moderately or highly accurate in determining disease status [34]. Second, we defined newly diagnosed DM with a single OGTT at baseline as suggested for epidemiological studies; however, this might lead to attenuation of the association between newly diagnosed DM and cardiovascular events, resulting in an underestimation of the risk in this group. Third, the duration of diabetes could be a factor that explains the conflicting results in studies aiming to determine diabetes as a $\mathrm{CHD}$ risk equivalent, since longer duration of diabetes is associated with an increased risk of CVD [29]. Recently, Dagenais et al in the Quebec Cardiovascular Study emphasized finding that compared to men with incident CVD, men with incident diabetes had a lower risk for CVD mortality during the first 5 years after the diagnosis of diabetes, but subsequently there was no difference between the 2 groups for cardiovascular and total mortality [35]. Finally, our population was selected from middle-aged Middle East Caucasians and therefore we cannot make inferences beyond a similar group.

\section{Conclusions}

The current study highlighted the finding that known diabetic patients in both genders and newly diagnosed diabetes especially in men, exhibited a CHD risk comparable to nondiabetics with a prior CHD, regardless of risk factors, furthermore diabetic subjects with prior $\mathrm{CHD}$ had the worst prognosis, by far more harmful in women than men; reinforcing thus the urgent need for intensive care and prophylactic treatment for cardiovascular diseases.

\section{Acknowledgements}

This study was supported by grant No. 121 from the National Research Council of the I.R. Iran. We express appreciation to the participants of district 13, Tehran and outcome committee particularly Dr. A. Ghanbarian and Dr. F. Eskandari. The linguistic help given by Ms N. Shiva is much appreciated.

\section{Author details}

${ }^{1}$ Prevention of Metabolic Disorders Research Center, Research Institute for Endocrine Sciences, Shahid Beheshti University of Medical Sciences, Parvaneh St., Yaman St., Velenjak, Tehran, Iran. Department of Epidemiology, School of Public Health, Shahid Beheshti University of Medical Sciences, Daneshjoo Blvd, Tehran, Iran. ${ }^{3}$ Endocrine Research Center, Research Institute for Endocrine Sciences, Shahid Beheshti University of Medical Sciences, Parvaneh St., Yaman St., Velenjak, Tehran, Iran.

\section{Authors' contributions}

$\mathrm{FH}$ (MD, associate professor of internal medicine and endocrinology) participated in the design of the study and drafting the manuscript. NF (MD, $\mathrm{MPH}$ ) performed the statistical analysis and participated in the drafting the manuscript. DK (MD, MPH, PhD Candidate in Epidemiology) participated in the statistical analysis and revised the manuscript critically for important intellectual content. FS (MD, assistant professor of cardiology) and FA (MD, professor of internal medicine and endocrinology) participated in the design of the study and all authors have given final approval of the version to be published.

\section{Competing interests}

The authors declare that they have no competing interests.

Received: 14 September 2010 Accepted: 4 December 2010 Published: 4 December 2010

\section{References}

1. Howard BV, Best LG, Galloway JM, Howard WJ, Jones K, Lee ET, Ratner RE, Resnick HE, Devereux RB: Coronary heart disease risk equivalence in diabetes depends on concomitant risk factors. Diabetes Care 2006 29:391-397.

2. Juutilainen A, Lehto S, Ronnemaa T, Pyorala K, Laakso M: Type 2 diabetes as a "coronary heart disease equivalent": an 18-year prospective population-based study in Finnish subjects. Diabetes Care 2005, 28:2901-2907.

3. Whiteley L, Padmanabhan S, Hole D, Isles C: Should diabetes be considered a coronary heart disease risk equivalent?: results from 25 years of follow-up in the Renfrew and Paisley survey. Diabetes Care 2005, 28:1588-1593.

4. Gruppetta M, Calleja N, Fava S: Long-term survival after acute myocardial infarction and relation to type 2 diabetes and other risk factors. Clin Cardiol 33:424-429.

5. Standards of medical care in diabetes-2009. Diabetes Care 2009, 32(Suppl 1):S13-61.

6. Cho E, Rimm EB, Stampfer MJ, Willett WC, Hu FB: The impact of diabetes mellitus and prior myocardial infarction on mortality from all causes and from coronary heart disease in men. J Am Coll Cardiol 2002, 40:954-960.

7. Evans JM, Wang J, Morris AD: Comparison of cardiovascular risk between patients with type 2 diabetes and those who had had a myocardial infarction: cross sectional and cohort studies. BMJ 2002, 324:939-942.

8. Vaccaro O, Eberly LE, Neaton JD, Yang L, Riccardi G, Stamler J: Impact of diabetes and previous myocardial infarction on long-term survival: 25year mortality follow-up of primary screenees of the Multiple Risk Factor Intervention Trial. Arch Intern Med 2004, 164:1438-1443.

9. Becker A, Bos G, de Vegt F, Kostense PJ, Dekker JM, Nijpels G, Heine RJ, Bouter LM, Stehouwer CD: Cardiovascular events in type 2 diabetes: comparison with nondiabetic individuals without and with prior cardiovascular disease. 10-year follow-up of the Hoorn Study. Eur Heart J 2003, 24:1406-1413. 
10. Stamler J, Vaccaro O, Neaton JD, Wentworth D: Diabetes, other risk factors, and 12-yr cardiovascular mortality for men screened in the Multiple Risk Factor Intervention Trial. Diabetes Care 1993, 16:434-444.

11. Nijjar AP, Wang H, Dasgupta K, Rabi DM, Quan H, Khan NA: Outcomes in a diabetic population of South Asians and whites following hospitalization for acute myocardial infarction: a retrospective cohort study. Cardiovasc Diabetol 2010, 9:4.

12. Diabetes Atlas. Brussels: International Diabetes Federation; 2006.

13. Hossain P, Kawar B, El Nahas M: Obesity and diabetes in the developing world-a growing challenge. N Engl J Med 2007, 356:213-215.

14. Hadaegh F, Bozorgmanesh MR, Ghasemi A, Harati H, Saadat N, Azizi F: High prevalence of undiagnosed diabetes and abnormal glucose tolerance in the Iranian urban population: Tehran Lipid and Glucose Study. BMC Public Health 2008, 8:176

15. Harati H, Hadaegh F, Saadat N, Azizi F: Population-based incidence of Type 2 diabetes and its associated risk factors: results from a six-year cohort study in Iran. BMC Public Health 2009, 9:186.

16. Ghassemi H, Harrison G, Mohammad K: An accelerated nutrition transition in Iran. Public Health Nutr 2002, 5:149-155.

17. Baynouna LM, Revel AD, Nagelkerke NJ, Jaber TM, Omar AO, Ahmed NM, Nazirudeen MK, Al Sayed MF, Nour FA, Abdouni S: Associations of cardiovascular risk factors in Al Ain, United Arab Emirates. CardiovasC Diabetol 2009, 8:21.

18. Hadaegh F, Harati H, Ghanbarian A, Azizi F: Prevalence of coronary heart disease among Tehran adults: Tehran Lipid and Glucose Study. East Mediterr Health J 2009, 15:157-166

19. Hadaegh F, Khalili D, Fahimfar N, Tohidi M, Eskandari F, Azizi F: Glucose intolerance and risk of cardiovascular disease in Iranian men and women: results of the 7.6-year follow-up of the Tehran Lipid and Glucose Study (TLGS). J Endocrinol Invest 2009, 32:724-730.

20. Azizi F, Ghanbarian A, Momenan AA, Hadaegh F, Mirmiran P, Hedayati M, Mehrabi Y, Zahedi-Asl S: Prevention of non-communicable disease in a population in nutrition transition: Tehran Lipid and Glucose Study phase II. Trials 2009, 10:5

21. prineas RjCR, Blackburn $\mathrm{H}$ : The minnesota code mannual of electrocardiographic findings: standards and procedures for measurement and classification. Boston: Wright-PSG; 1982

22. Ford ES, Giles WH, Croft JB: Prevalence of nonfatal coronary heart disease among American adults. Am Heart J 2000, 139:371-377.

23. Hadaegh F, Khalili D, Ghasemi A, Tohidi M, Sheikholeslami F, Azizi F: Triglyceride/HDL-cholesterol ratio is an independent predictor for coronary heart disease in a population of Iranian men. Nutr Metab Cardiovasc Dis 2009, 19:401-408.

24. Haffner SM, Lehto S, Ronnemaa T, Pyorala K, Laakso M: Mortality from coronary heart disease in subjects with type 2 diabetes and in nondiabetic subjects with and without prior myocardial infarction. $N$ Engl J Med 1998, 339:229-234

25. Schramm TK, Gislason GH, Kober L, Rasmussen S, Rasmussen JN, Abildstrom SZ, Hansen ML, Folke F, Buch P, Madsen M, et al: Diabetes patients requiring glucose-lowering therapy and nondiabetics with a prior myocardial infarction carry the same cardiovascular risk: a population study of 3.3 million people. Circulation 2008, 117:1945-1954.

26. Lee CD, Folsom AR, Pankow JS, Brancati FL: Cardiovascular events in diabetic and nondiabetic adults with or without history of myocardial infarction. Circulation 2004, 109:855-860.

27. Hu FB, Stampfer MJ, Solomon CG, Liu S, Willett WC, Speizer FE, Nathan DM, Manson JE: The impact of diabetes mellitus on mortality from all causes and coronary heart disease in women: 20 years of follow-up. Arch Intern Med 2001, 161:1717-1723.

28. Krempf M, Parhofer KG, Steg PG, Bhatt DL, Ohman EM, Rother J, Goto S, Pasquet B, Wilson PW: Cardiovascular event rates in diabetic and nondiabetic individuals with and without established atherothrombosis (from the REduction of Atherothrombosis for Continued Health [REACH] Registry). Am J Cardiol 2010, 105:667-671.

29. Gonzalez-Clemente JM, Palma S, Arroyo J, Vilardell C, Caixas A, GimenezPalop O, Delgado-Rodriguez M: [Is diabetes mellitus a coronary heart disease equivalent? Results of a meta-analysis of prospective studies]. Rev Esp Cardiol 2007, 60:1167-1176.

30. Eberly LE, Cohen JD, Prineas R, Yang L: Impact of incident diabetes and incident nonfatal cardiovascular disease on 18-year mortality: the multiple risk factor intervention trial experience. Diabetes Care 2003, 26:848-854.

31. Carnethon MR, Biggs ML, Barzilay J, Kuller LH, Mozaffarian D, Mukamal K, Smith NL, Siscovick D: Diabetes and coronary heart disease as risk factors for mortality in older adults. Am J Med 2010, 123:556-559, e551.

32. Andersson C, Gislason GH, Weeke P, Hoffmann S, Hansen PR, TorpPedersen C, Sogaard P: Diabetes is associated with impaired myocardial performance in patients without significant coronary artery disease. Cardiovasc Diabetol 2010, 9:3.

33. Esteghamati A, Abbasi M, Nakhjavani M, Yousefizadeh A, Basa AP, Afshar H: Prevalence of diabetes and other cardiovascular risk factors in an Iranian population with acute coronary syndrome. Cardiovasc Diabetol 2006, 5:15.

34. Barr EL, Zimmet PZ, Welborn TA, Jolley D, Magliano DJ, Dunstan DW, Cameron AJ, Dwyer T, Taylor HR, Tonkin AM, et al: Risk of cardiovascular and all-cause mortality in individuals with diabetes mellitus, impaired fasting glucose, and impaired glucose tolerance: the Australian Diabetes, Obesity, and Lifestyle Study (AusDiab). Circulation 2007, 116:151-157.

35. Dagenais GR, St-Pierre A, Gilbert P, Lamarche B, Despres JP, Bernard PM, Bogaty P: Comparison of prognosis for men with type 2 diabetes mellitus and men with cardiovascular disease. Cmaj 2009, 180:40-47.

doi:10.1186/1475-2840-9-84

Cite this article as: Hadaegh et al: New and known type 2 diabetes as coronary heart disease equivalent: results from 7.6 year follow up in a middle east population. Cardiovascular Diabetology 2010 9:84.

\section{Submit your next manuscript to BioMed Central and take full advantage of:}

- Convenient online submission

- Thorough peer review

- No space constraints or color figure charges

- Immediate publication on acceptance

- Inclusion in PubMed, CAS, Scopus and Google Scholar

- Research which is freely available for redistribution

Submit your manuscript at www.biomedcentral.com/submit
C) Biomed Central 